المخطط الوطني للتنمية الفلاحية ودوره في التنمية المحلية في الجزائر حالة ولاية البرج زهير صيفي

قسم علوم الأرض جامعة محمد خيضر بسكرة الجزائر

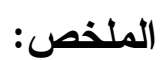

يثكل القطاع الفلاحي أولوية في السياسات الاقتصادية للجز ائر منذ الاستقلال وييرز ذلـــــ من خلال التشريعات و النصوص القانونية وتغيير الملكية العقارية التي مر بها هذا القطاع، ابتداء

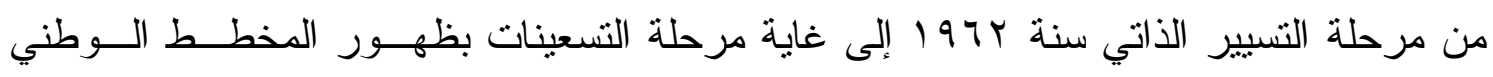

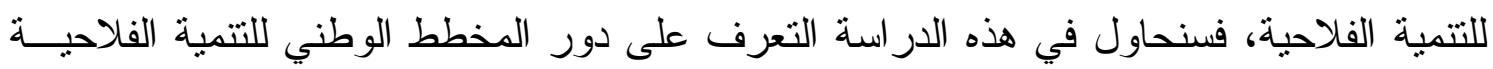
في التنمية المحلية على مستوى و لاية البرج

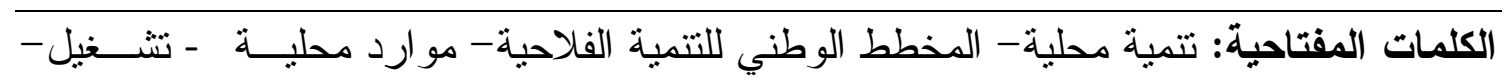
إنتاج Received on: 9/11/2014 Accepted for publication on: 19/112014

Referees: Prof. Mohamed J. Rashid Prof. Samia A. Hilal 
تحتل الزر اعة مكانة بالغة الأهمية في اقتصاديات الدول النامية، فهي تعنبر بالنسبة لمعظم

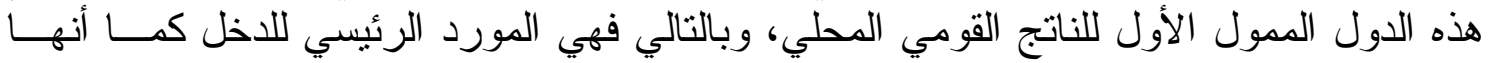

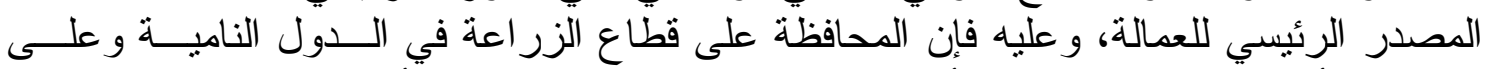

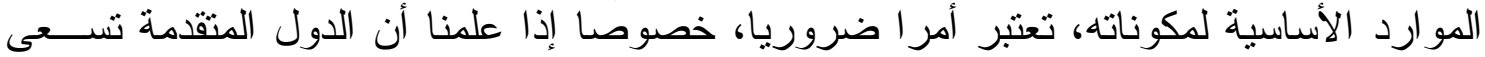

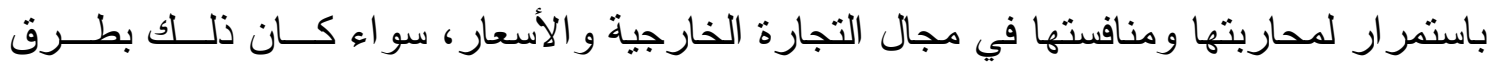

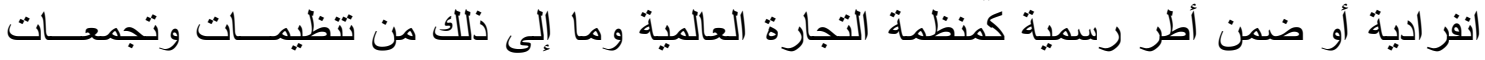

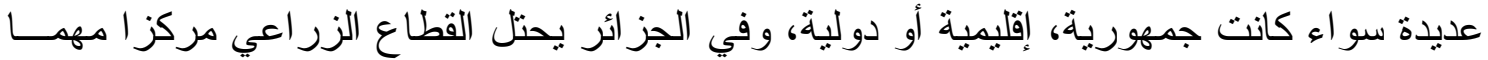

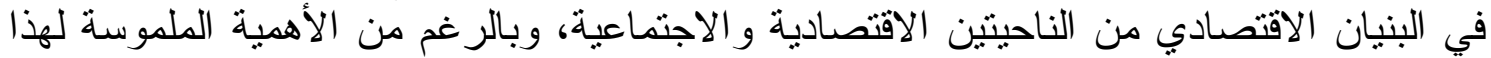

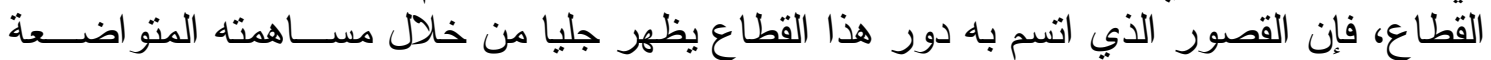

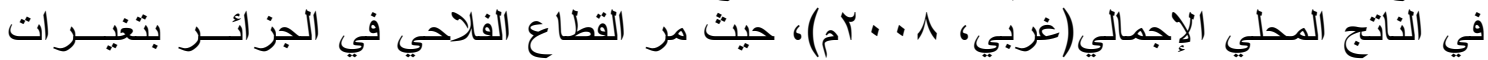

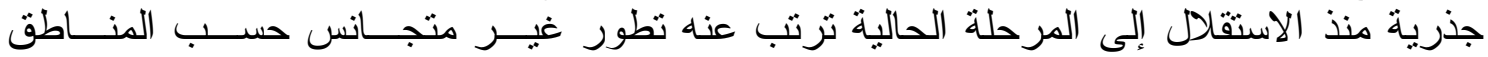

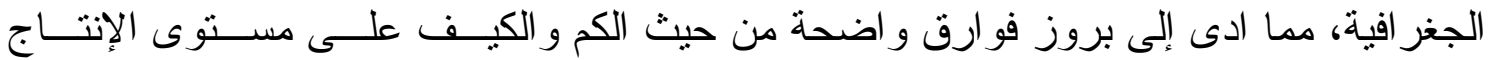

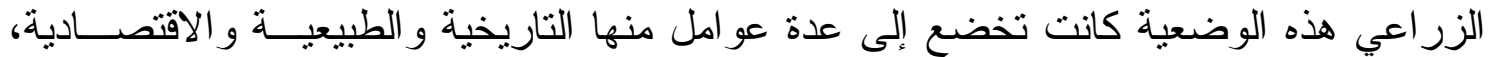

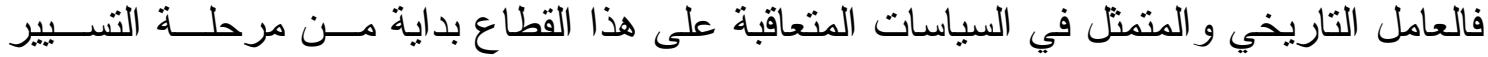

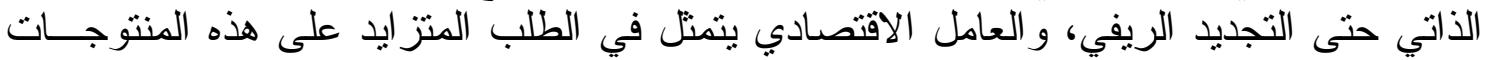

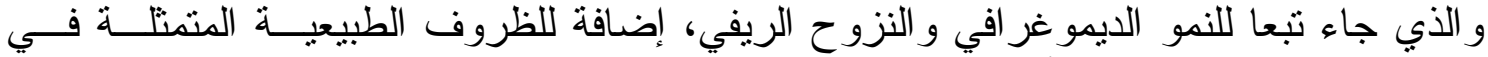

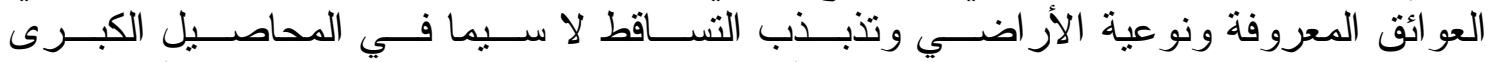

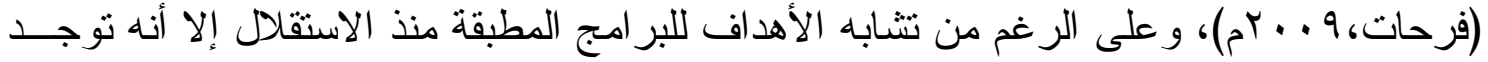

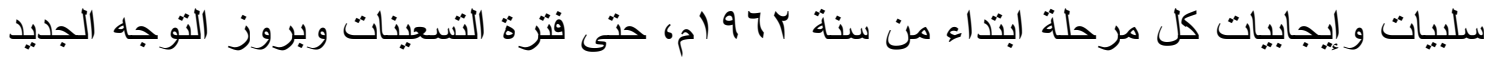

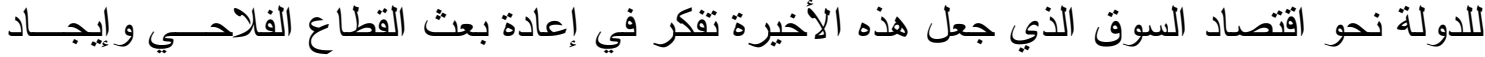

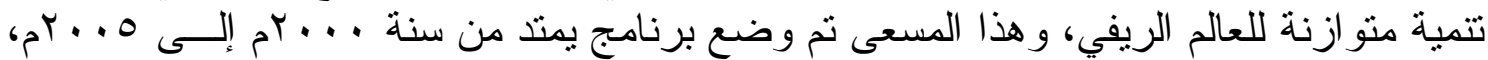
اطلق عليه المخطط الوطني للتنمية الفلاحية(P.N.D.A)، فسنحاول في هذه الدر اســـة التعـرف

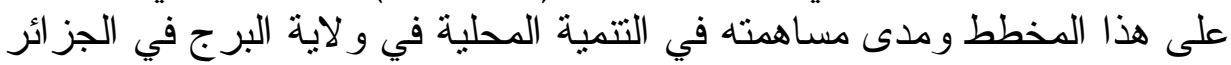

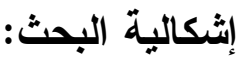

رغم المجهودات الكبيرة التي تبذلها الدولة الجزائرية من اجل النهوض بالقطاع الفلاحسي التهي

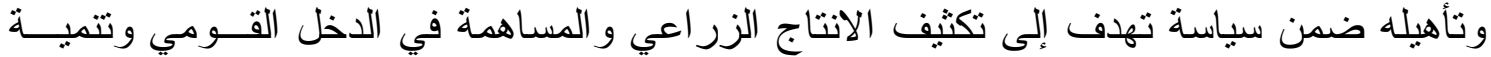

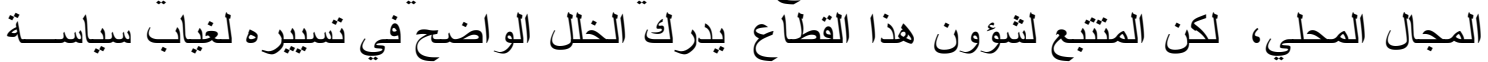

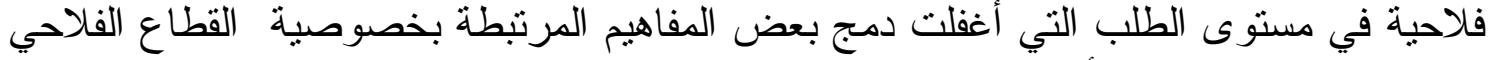

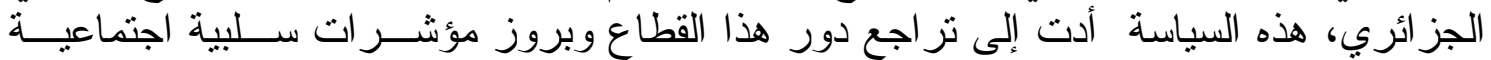

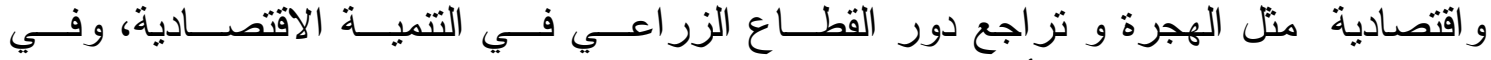

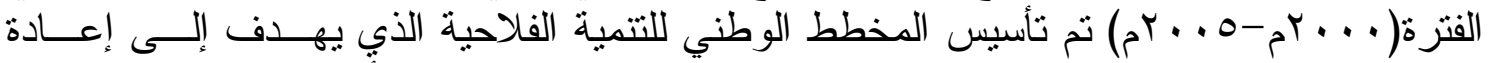

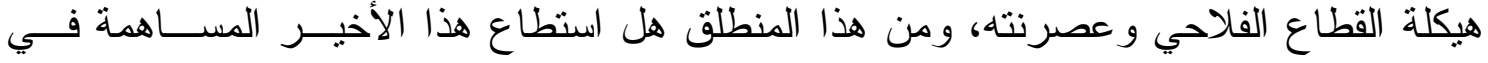

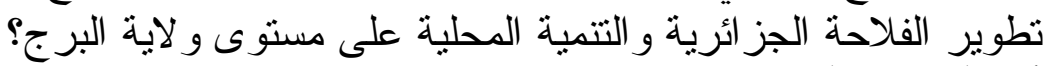

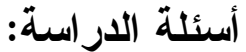

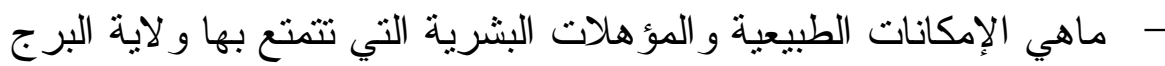

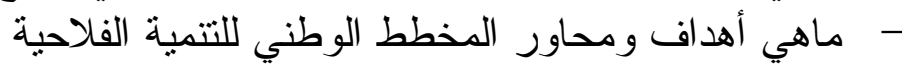
- - ما هي وسائل تتفيذ المخطط الوطني للتنمية الفلاحية - - هل فعلا ساهم المخطط الوطني للتتمية الفلاحية في التتمية المحلية لو لاية البرجية 
أهداف البحث:

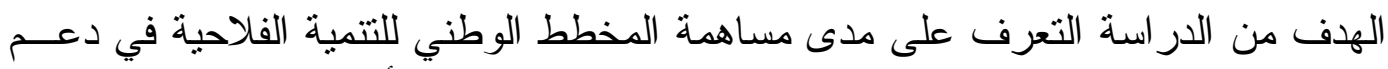
التتمية المحلية ومدى فعالة هذا المخطط على القطاع الفلاحي، باعتبار أن التتمية المحلية حصيلة

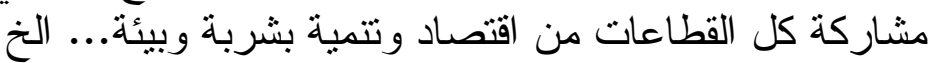
فرضيات الار اسةة: - و لائية البرج لات تحتوي على مقومات طبيعية وبشرية للنهوض بالقطاع الفلاحي و المساهمة في التنمية المحلية الانة

- غياب إطار قانوني وتقني وتدعيم مالي ادى إلى فنثل تطبيق المخطط الوطني للتتمية الفلاحية

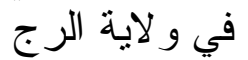

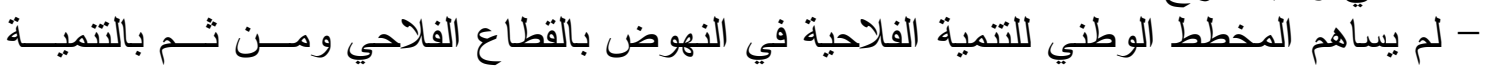
المحلية

- ساهم المخطط الوطني للتنمية الفلاحية ولو بشكل جزئي في تطوير القطاع الفلاحي في منطقة

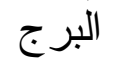
منهجية الار اسة:

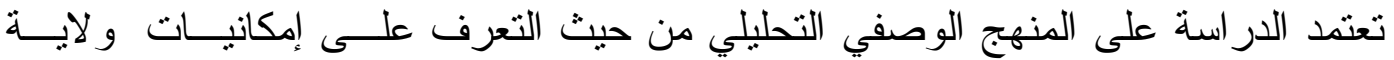

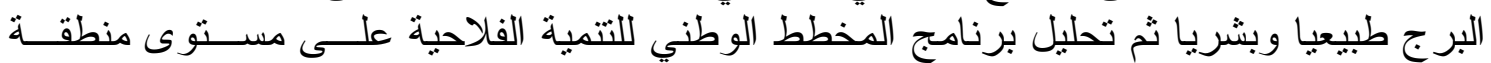

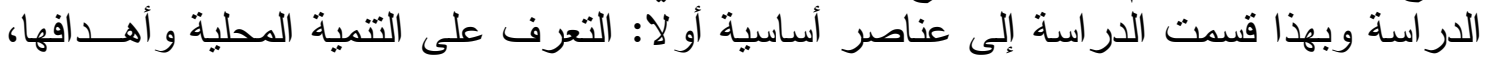

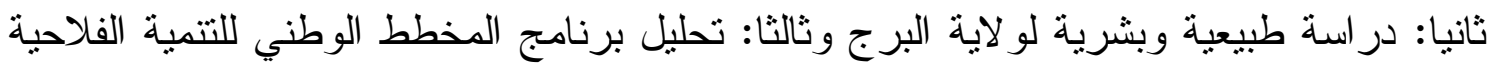

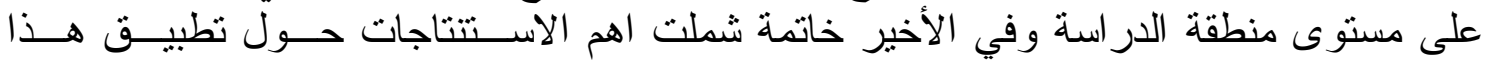

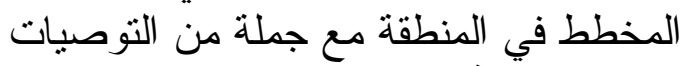
حدود الار أسة: - الحدود النظرية: يعتبر موضوع التتمية الفلاحية من المو اضيع المهمة التي يمكن در استه مــن

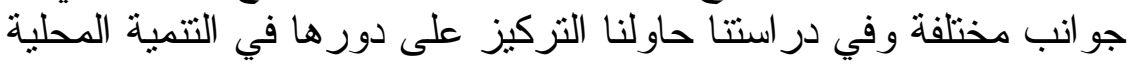

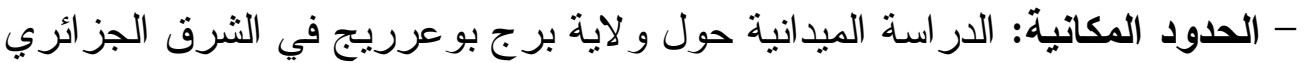

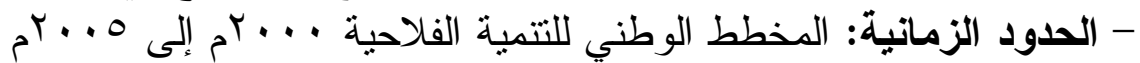
الار اسات السابقة: الزمائة:

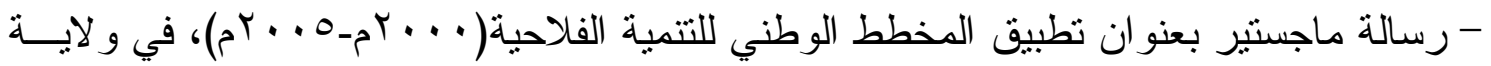

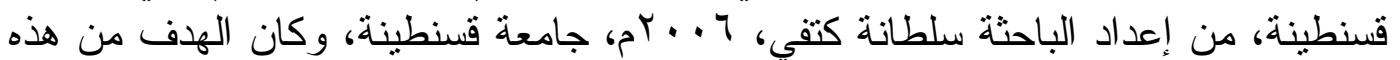
الدر اسة تقييم نتائج المخطط الوطني للتنمية الفلاحة على مستوى و لاية قسنطينة - رسالة ماجستير بعنوان إنتاج الحليب في ظل المخطط الوطني للتنمية الفلاحية بولاية قسنطينة

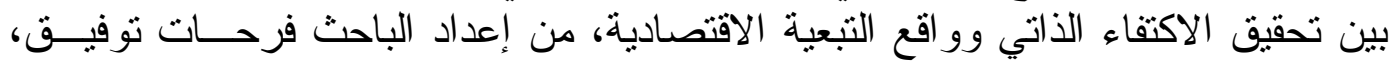

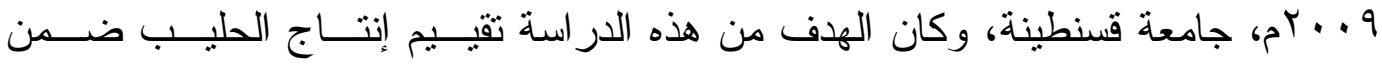

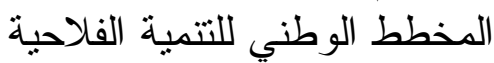

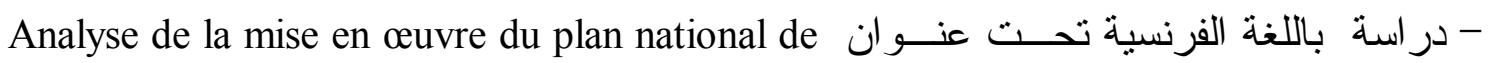
développement agricole dans la première tranche du périmeter de la mitidja oust algérie

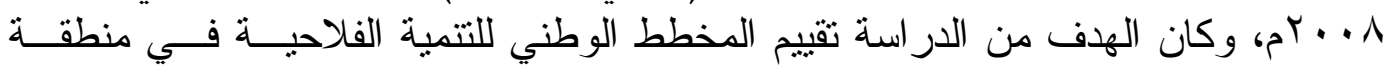
المتيجة أولا: التنمية المحلية: 1- 1 - مفهوم التنمية المحلية: المجية:

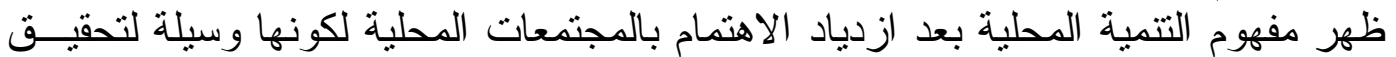

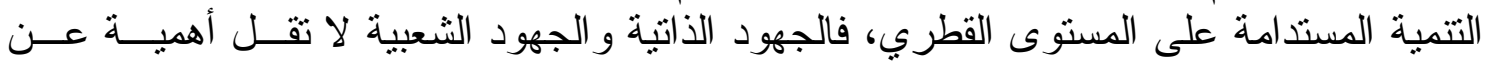


الجهود الحكومية في تحفيق التتمية عبر مساهمة السكان في وضع وتتفيذ مشروعات التتمية، مما

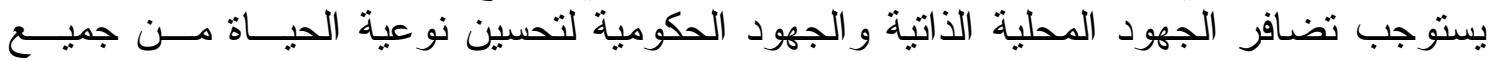

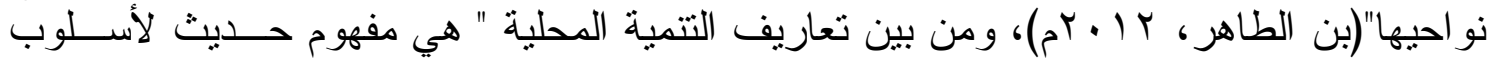

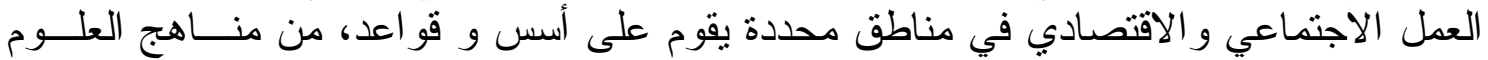

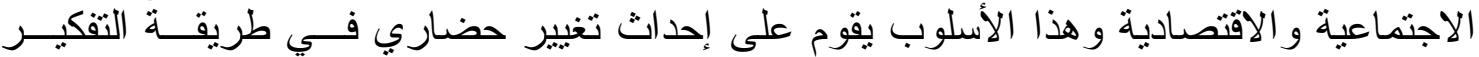

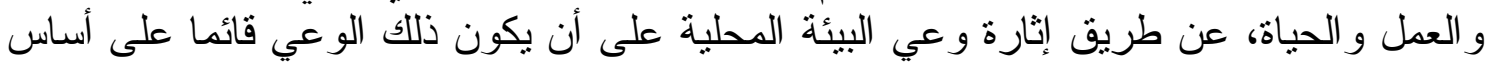

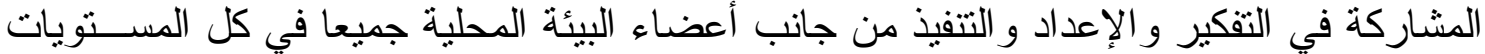

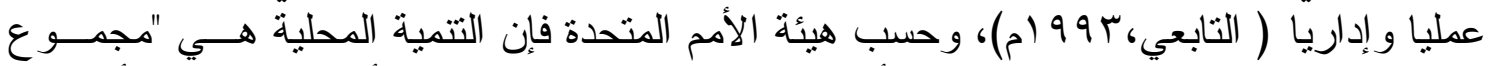

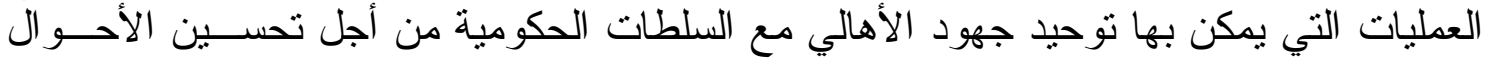

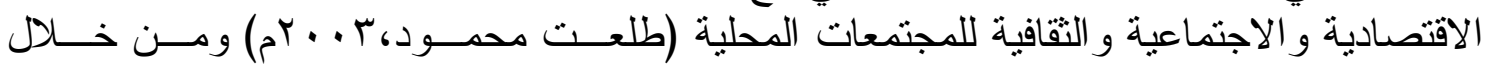
التعاريف السابقة فإن التتمية المحلية عبارة عن أسلوب عمل جماعي، لإحداث تغيير هذا التغييــر

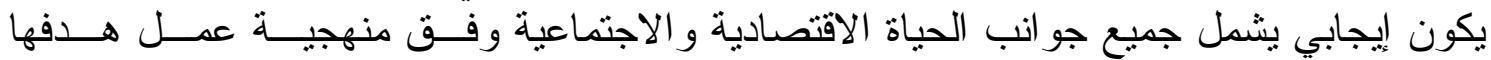

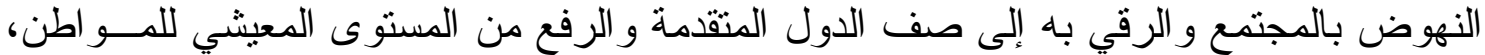

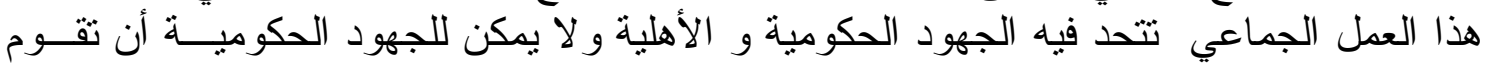
وحدها بكل متطلبات التتمية وعملياتها، لذلك من الضروري مشاركة المو اطنين في وضع وتتفيذ

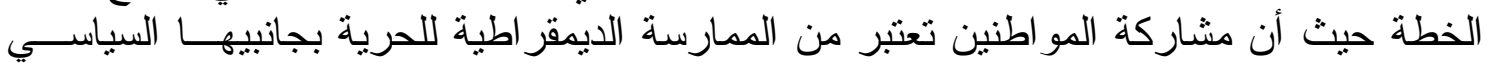

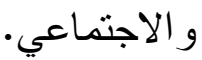

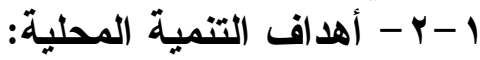

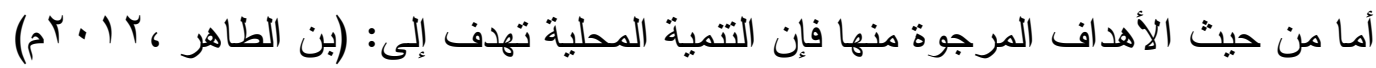

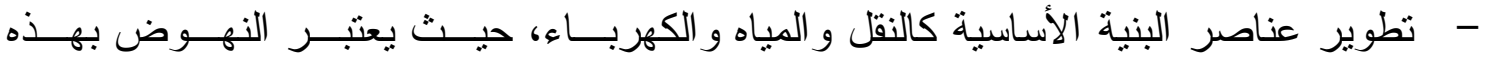

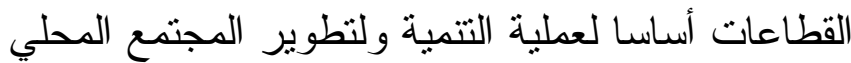

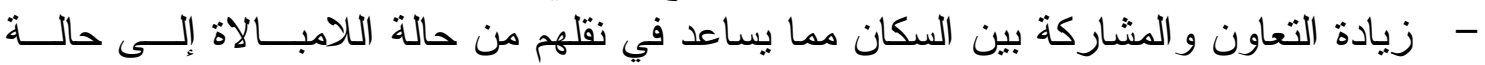
المشاركة الفاعلة

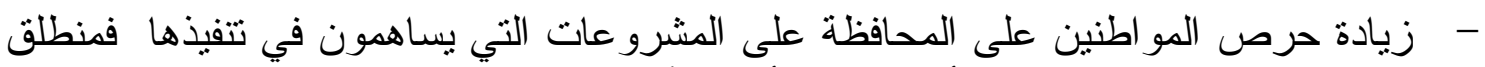
التتمية المحلية، إذن هو مبدأ البناء من أسفل بأن نجعل من تتمية الجماعات المحلية، نقطة

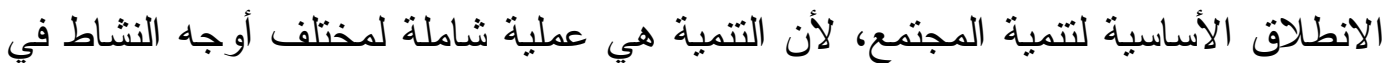

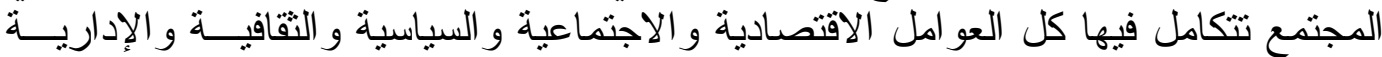
بمعنى أنها نتمل كل القطاعات، وهي مفهوم كلي وشامل يتضمن تثمين الإمكانيات الذاتية المتوفرة للاقتصاد الوطني وتعتمد على نوعية الإنسان لأنه أساس التغيير و التنظيم و التحكم

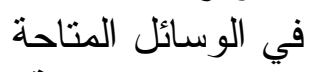

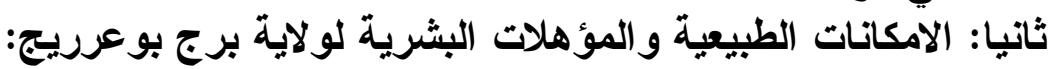

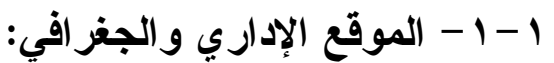

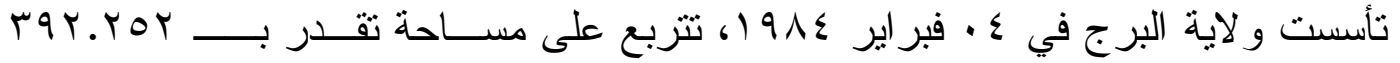

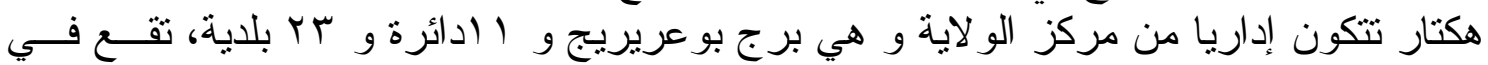

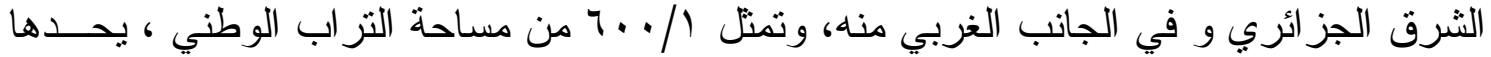

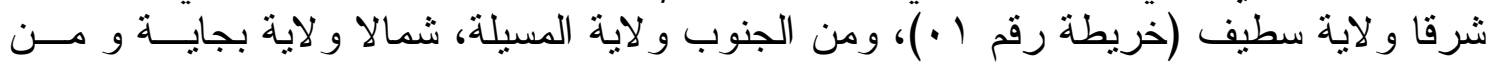

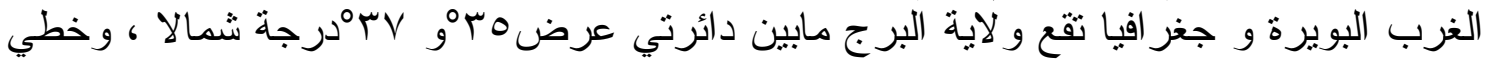

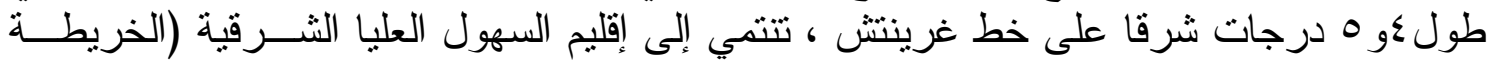

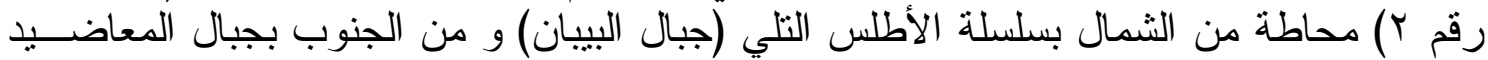
ومن ناحية الثرق بسهول من سطيف. (الإمكانات الطبيعية: أ- التضاريس: تلتوعان في التوزيع مع سيطرة مجال السهول 
حسب معطيات الجدول رقم (1 (·) و الخريطة رقم (ب ·)، نجد أربع وحدات طبيعية تغطي

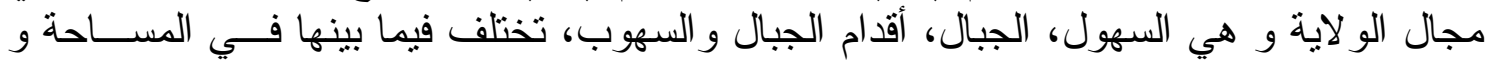

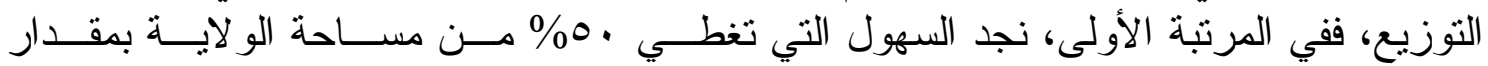

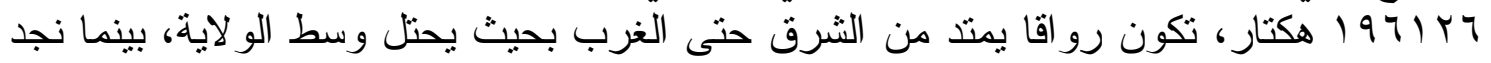

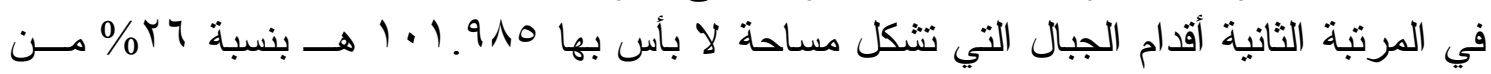

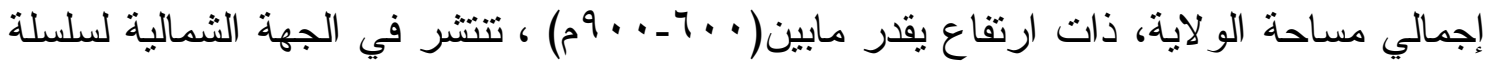

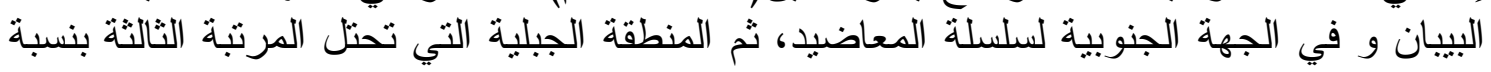

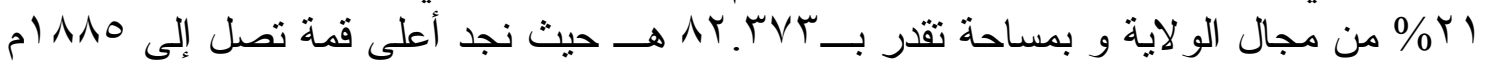

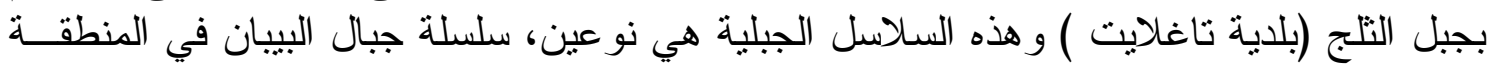

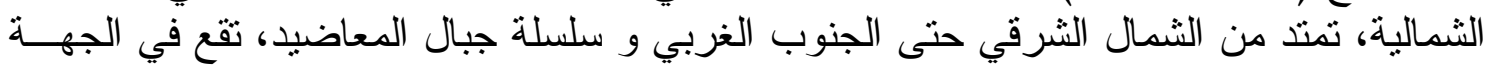

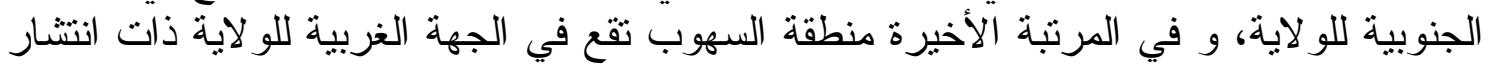

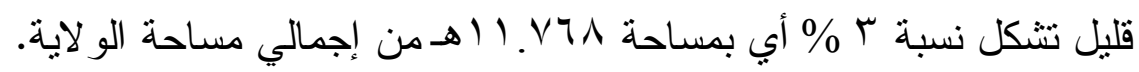

جدول رقم (1): " توزيع تضاريس ولاية البرج "

\begin{tabular}{|c|c|c|c|}
\hline التوزيع الجغرافي & النسبة \% & المساحة (هـ) & التضاريس \\
\hline الجنوب و الثلمال تحدها سلسلة المعاضيد عين ز ادة في الثرب ثنية وفي النصر & 0. & $197.1 \times 7$ & السهول \\
\hline الجهة الثمالية لجبال البيبان و الجهة الجنوبية لجبال المعاضيد & ry & $1 \cdot 1.910$ & أقدام الجبال \\
\hline سلسلة جبال البيبان في الثمال، المعاضيد الجهة الجنوبية & YI & AT.TVT & الجبال \\
\hline الجهة الجنوبية الغربية & r & 11.871 & 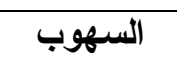 \\
\hline l & $1 \cdots$ & TQY.YOT & 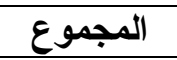 \\
\hline
\end{tabular}
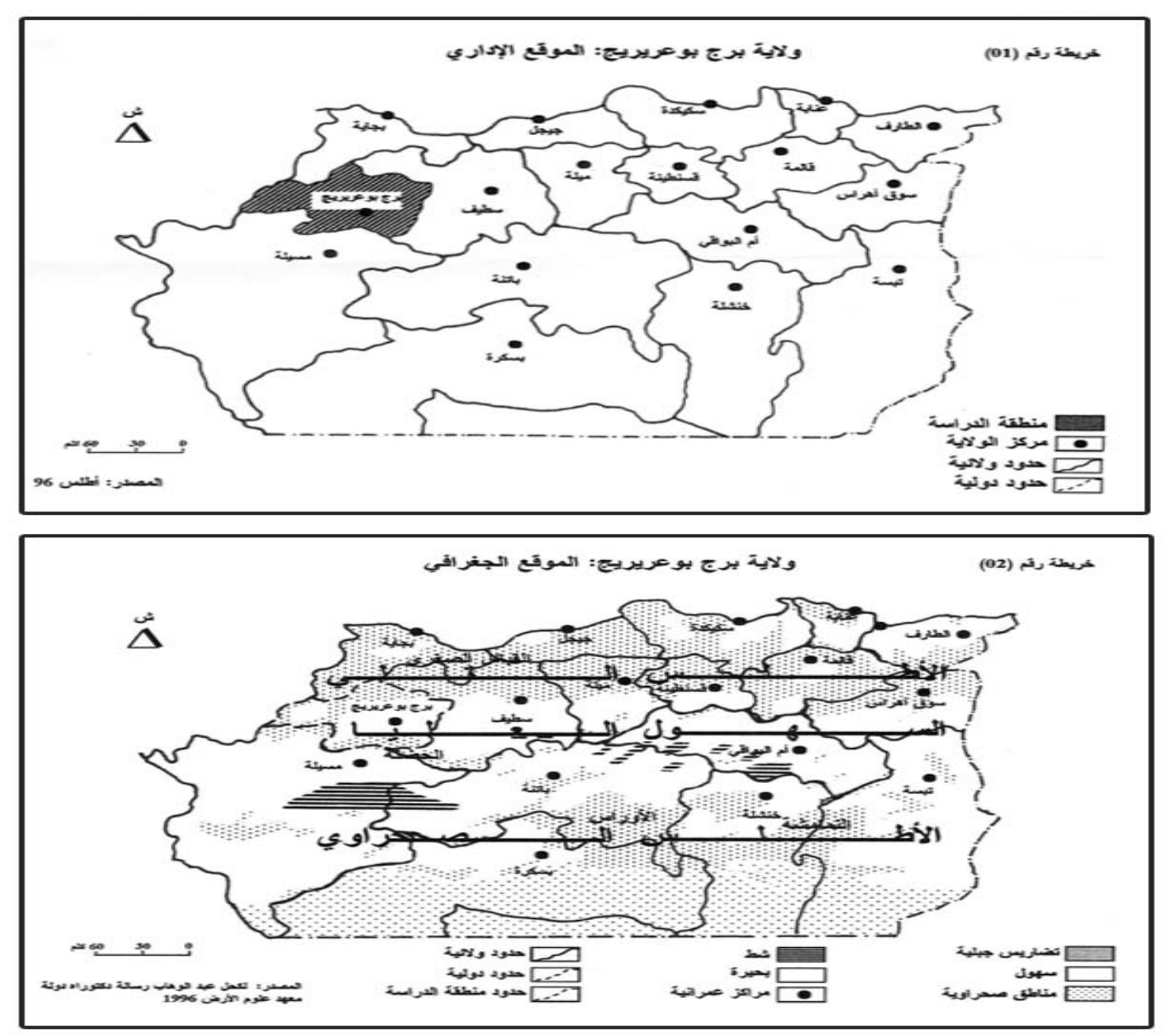
ب- المناخ: انتشار و اسع للمناخ الثبه الرطب ذو الثتاء الدافئ

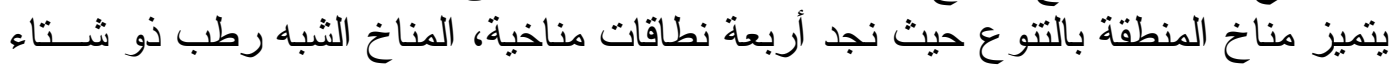

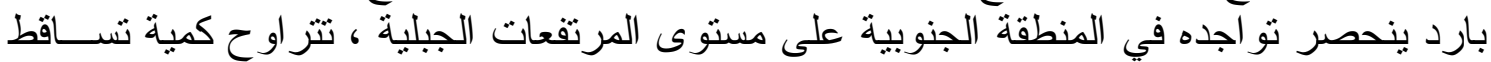

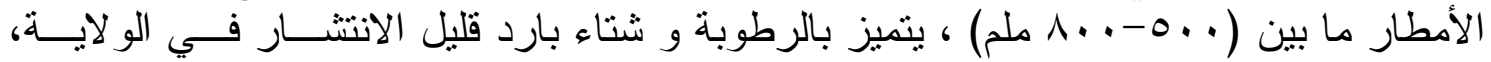

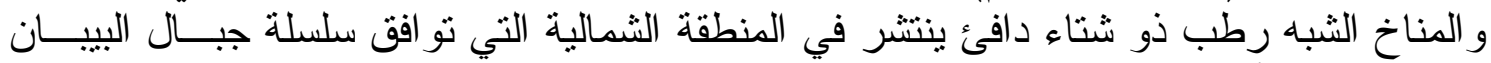

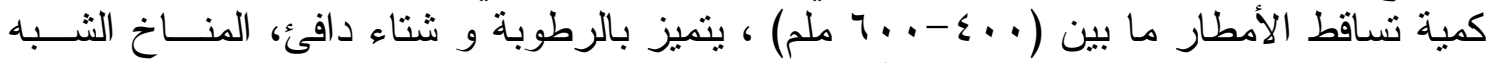

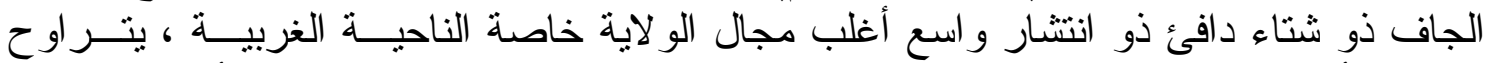

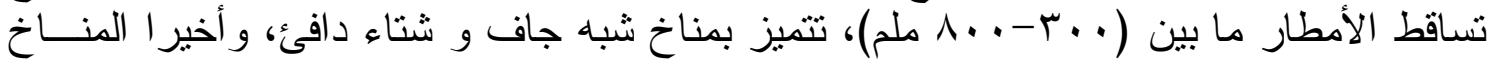

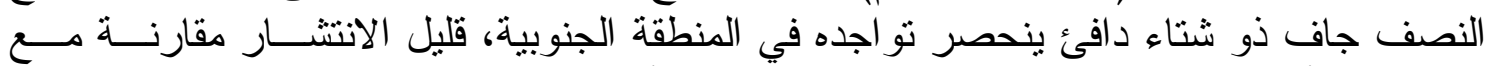

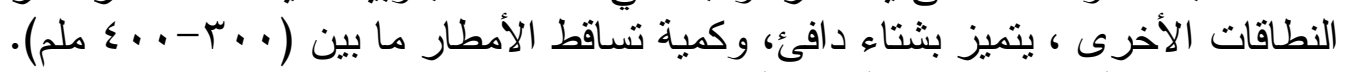

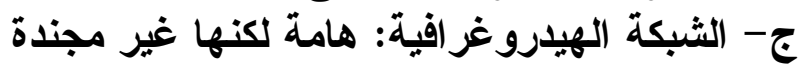

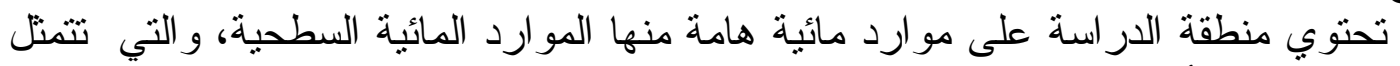

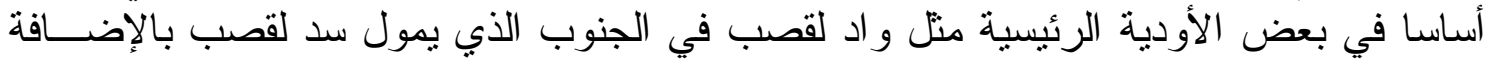

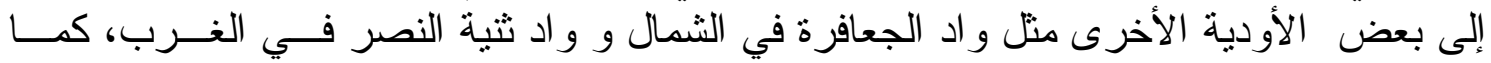

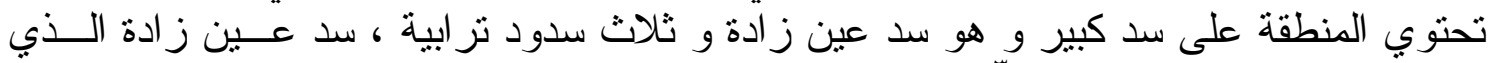

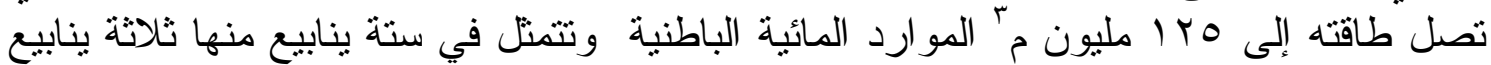

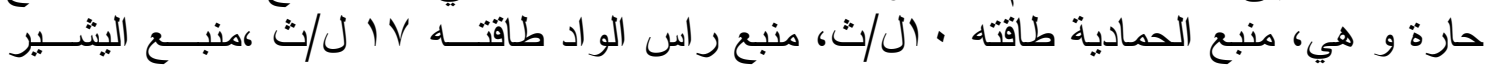

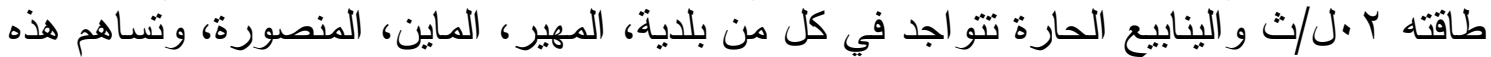

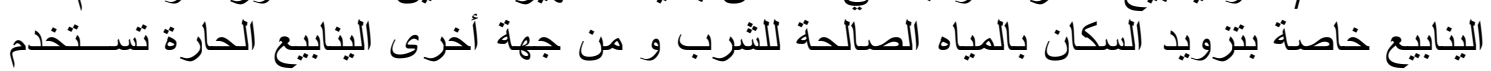
للحمامات.

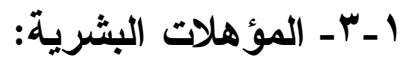

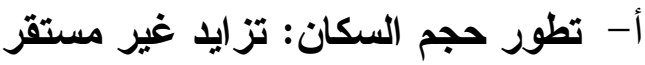

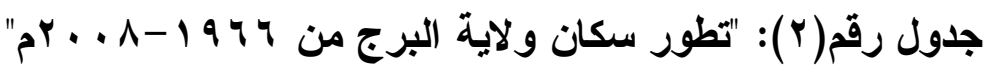

\begin{tabular}{|c|c|c|c|c|c|}
\hline$r \ldots \Lambda$ & 1991 & $19 \wedge \mathrm{V}$ & $19 V V$ & 1977 & السنة \\
\hline 791010 & Trr...9 & 517710 & $|V \pi| \mid V$ & 117717 & عدد السكان(ن) \\
\hline
\end{tabular}

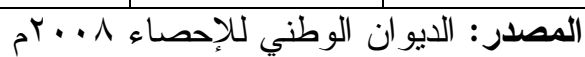

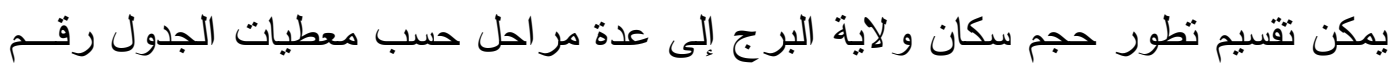

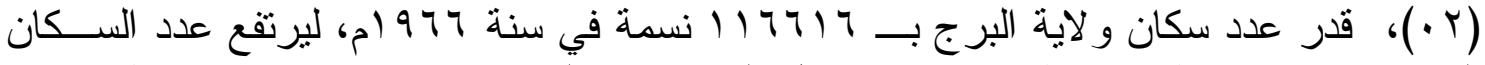

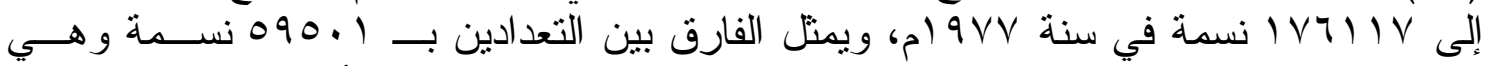
زيادة ضعيفة في هذه الفترة ، وفي سنة 9 و ام نسجل

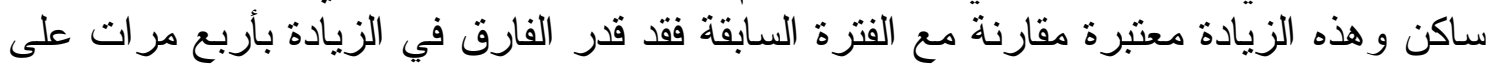

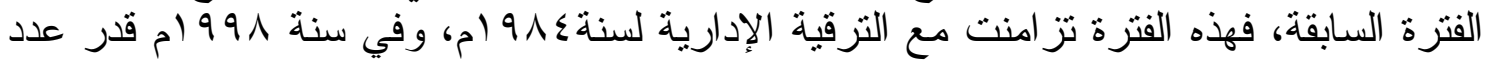

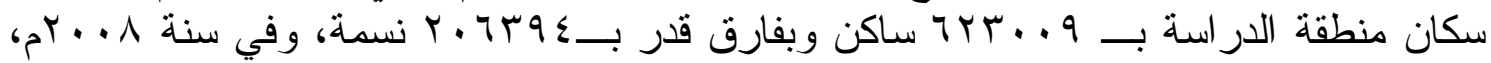

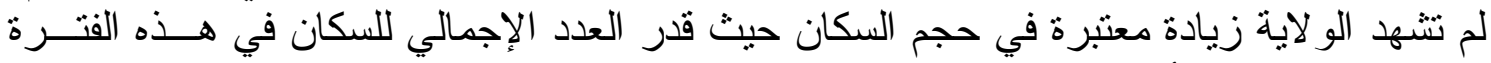

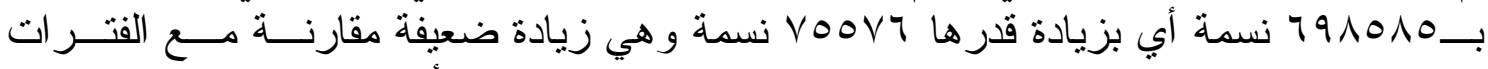

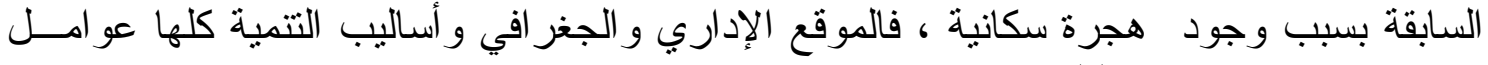
ساهمت في تهميش هذه البلديات

ب-الكثافة السكانية: تتناقص كلما اتجهنا من مركز الولاية نحو الأطر اف

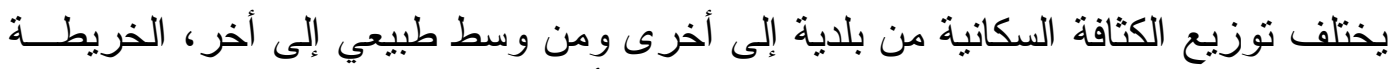

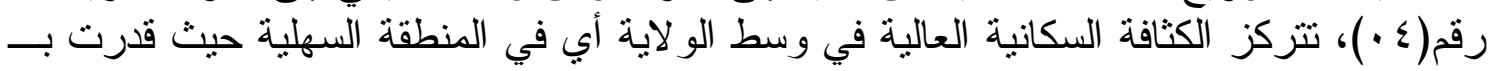




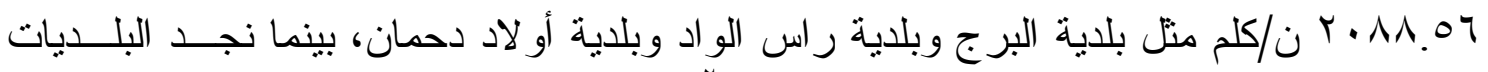

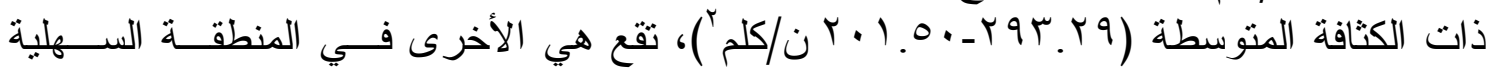

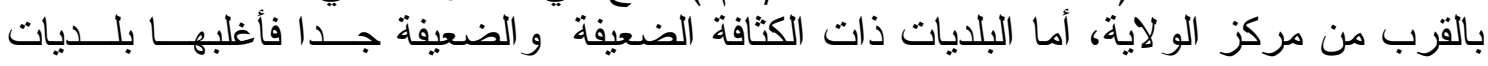

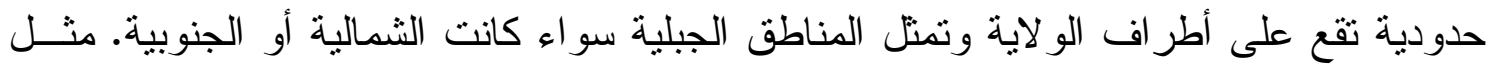

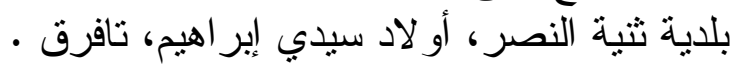
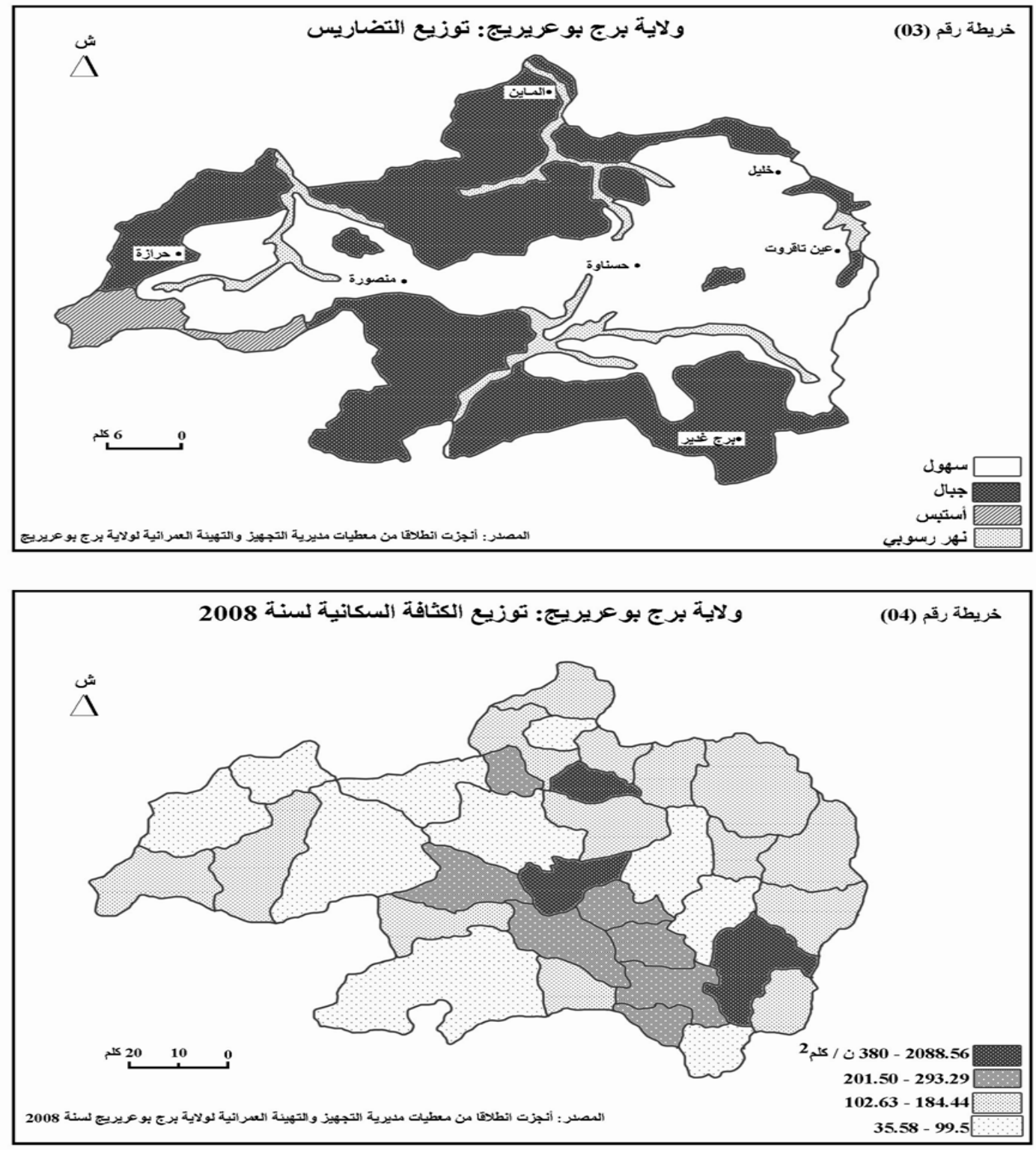

ثالثا: تطبيق المخطط الوطني للتنمية الفلاحية في ولاية البرج: r- 1 - المخطط الوطني للتنمية الفلاحية: أ- تعريف المخطط الوطني للتنمية الفلاحية:

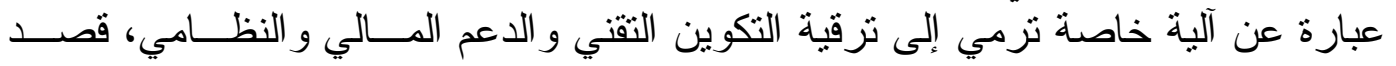

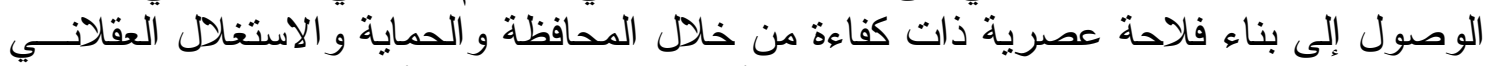

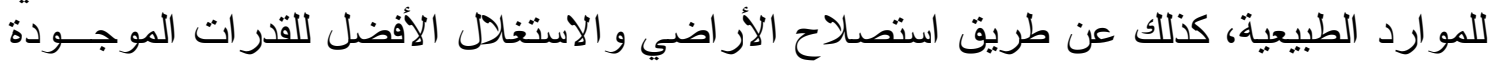

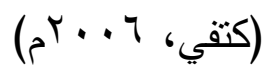
ب- أهداف المخطط الوطني: 
1 - الحماية و الاستغلال العقلاني و الدائم للمو ارد الطبيعية r- الاندماج في الاقتصاد الوطني والإني الإنفي

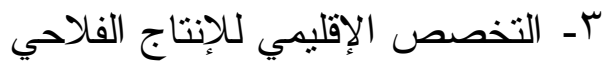
ع - إعادة هيكلة المجال الفلاحي و إعادة الاعتبار وتأهيل الموارد الطبيعية لمختلف جهـات

الوطن 0- تحسين الإنتاجية وزيادة حجم الإنتاج الفلاحي 7 - تحسين ظروف الحياة ومداخيل الفلاحين

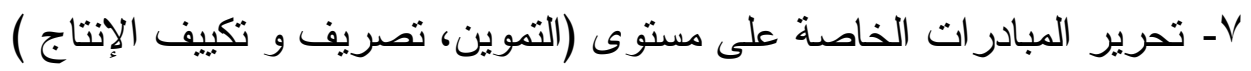
A- ترقية ونشجيع الاستثمار الفلاحي

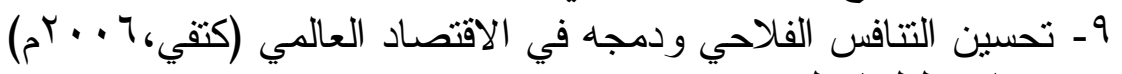

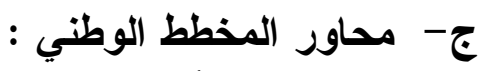
$\checkmark$ - - - البر امج الموجهة لإعادة تأهيل و عصرنة المستثمر ات الفلاحية وتربية المو اثي - برنامج تكثيف الإنتاج وتحسين الإنتاجية - - برنامج تكثيف أساليب الإنتاج - - برنامج نظوير الإنتاج الفلاحي

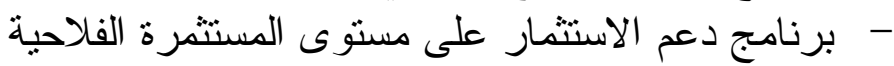

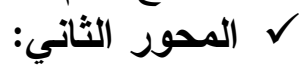
- البرنامج الوطني للتشجير الذي يهدف إلى حماية البيئة وتثمين المناطق الجبلية - برنامج التشغيل الريفي - برنامج استصلاح الأر اضي عن طرئ طريق الامتياز

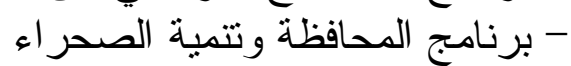
و قد سطرت أهداف المخطط حسب بر امجه لتحقيق ثنلاث مهام أساسية وهي:

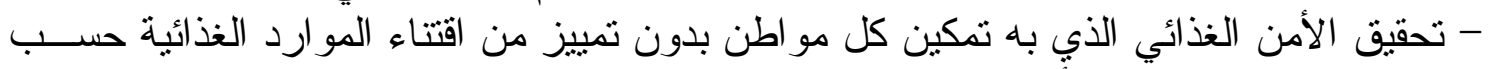

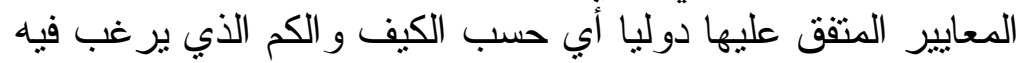

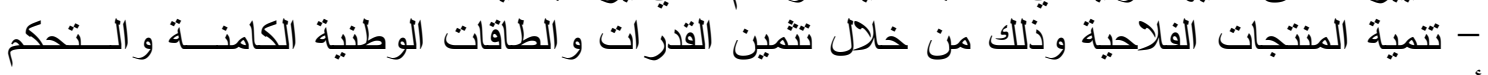
أكثر في العو ائق الطبيعية

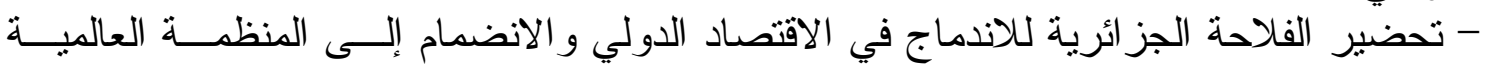
للتجارة د - لبجارة وسائل تتفيذ المخطط الوطني للتنمية:

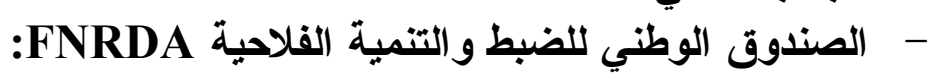

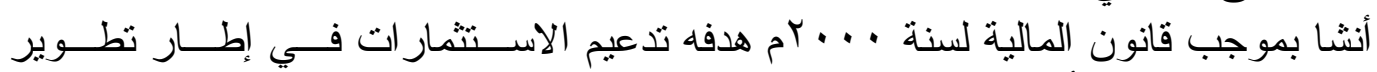

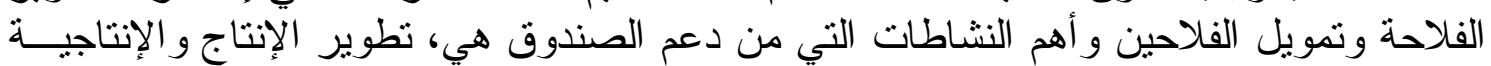

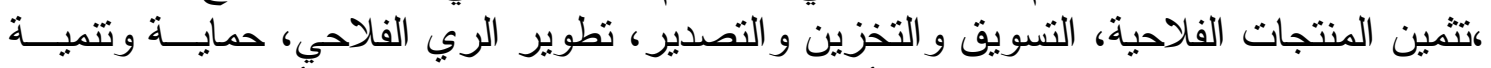

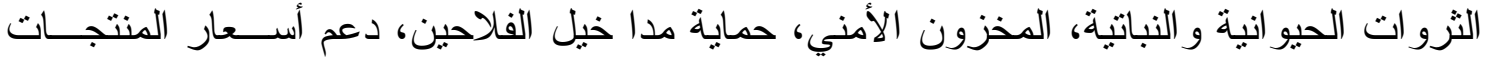
الطاقوية المستعملة في الفلاحة، تخفيض نسب فئ فو ائد القروض الته الفلاحية.

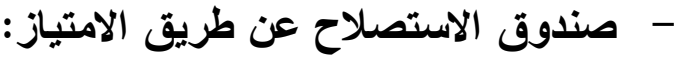

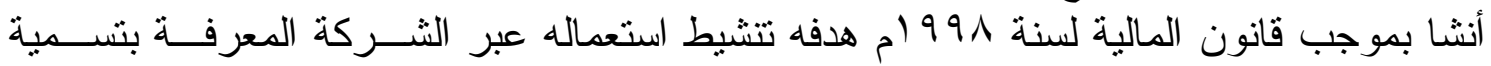

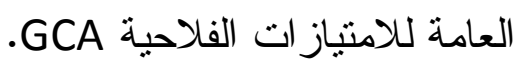
- القرض الفلاحي والتأمينات الاقتصادية: 


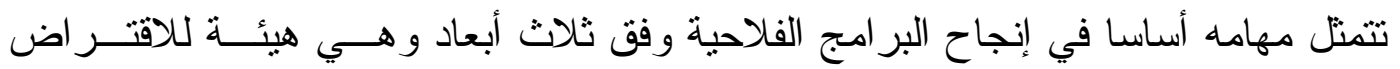

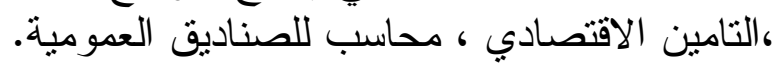

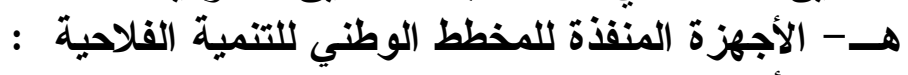

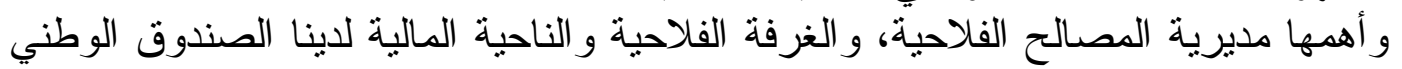
للتعاون الفلاحي بنك الفلاحة و التتمية الريفية.

r-r - - دور المخطط الوطني للتنمية الفلاحية في التنمية المحلية في ولاية البرج:

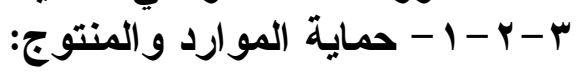

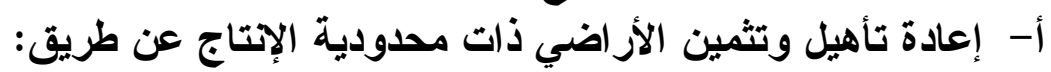

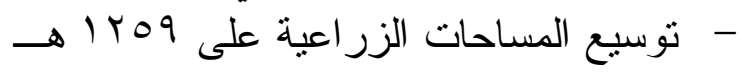

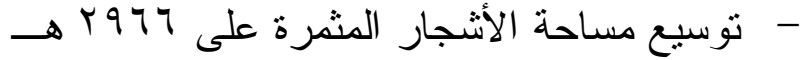

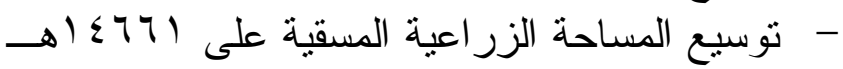

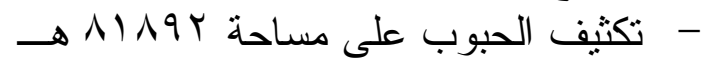

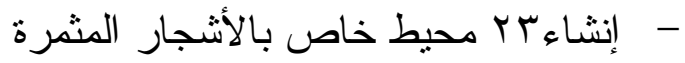
ب -تأهيل المستثمر ات الفلاحية:

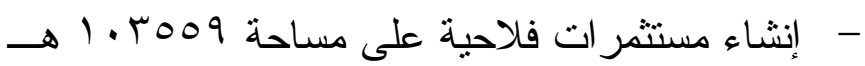

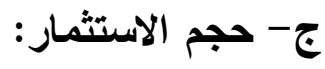

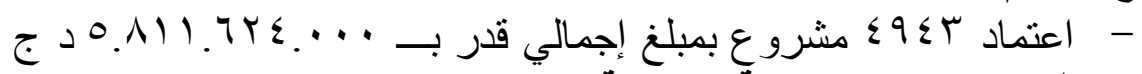
د - تطوير الهياكل القاعدية الفلاحية:

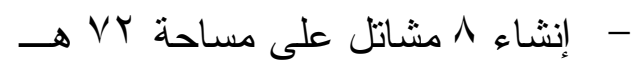

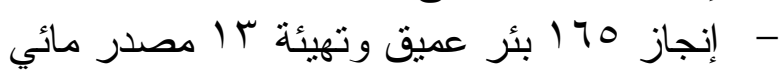

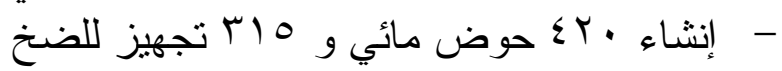

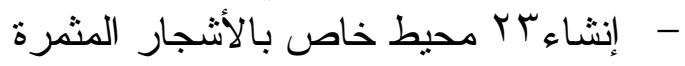

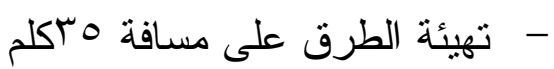

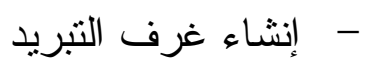
-

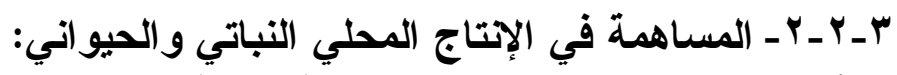

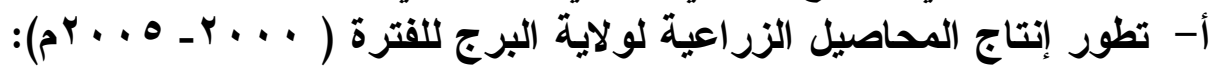

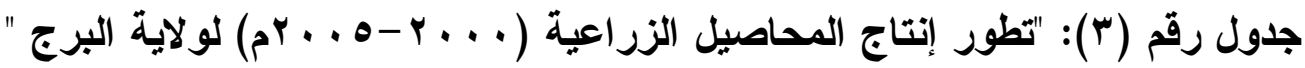

\begin{tabular}{|c|c|c|c|c|}
\hline أشجار مثمرة & أعلاف & بقـــول جافة وخضر اوات & حبوب & السنوات \\
\hline$V \Gamma 999$ & $1 \vee 9 \ldots$ & 91000 & ITVO.0 & $r \ldots$ \\
\hline 09901 & $1.0 T \leqslant Y$ & $1 \pi \varepsilon .9 \pi$ & ะqrหq. & $r \ldots 1$ \\
\hline $1.791 \mathrm{~V}$ & WYY & TMYIE & YY $\leqslant 0$. & $r \ldots r$ \\
\hline $10 \leqslant V \cdot \varepsilon$ & r.OV^. & 1.190. & $1 . \leqslant r \wedge \ldots$ & $r \ldots r$ \\
\hline IYKR.. & $\varepsilon, Y \backslash V$. & $\Lambda .1 \ldots$ & 9 qr... & $r \ldots \varepsilon$ \\
\hline$\ldots, \ldots$ & $1 \leq . Y 0$. & $941 \ldots$ & 1.1119 & $r \ldots o$ \\
\hline
\end{tabular}

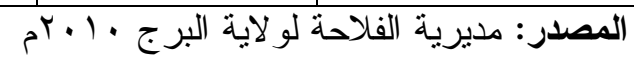

شكل رقم (1) "تظور إنتاج المحاصيل الزراعية ( . . . ץ-ه . . بم) لولاية البرج " \begin{tabular}{r|l}
1200000 & \\
1000000 & \\
800000 & \\
\hline
\end{tabular} 


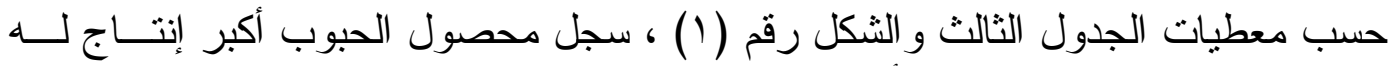

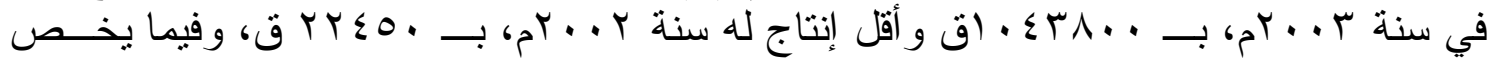

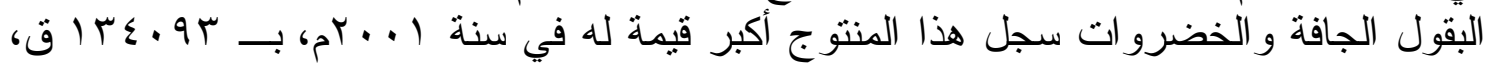

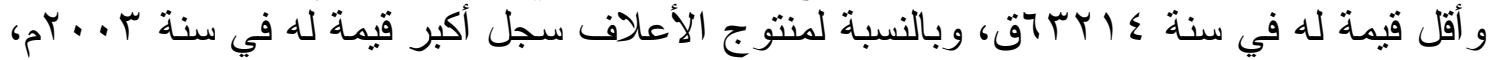

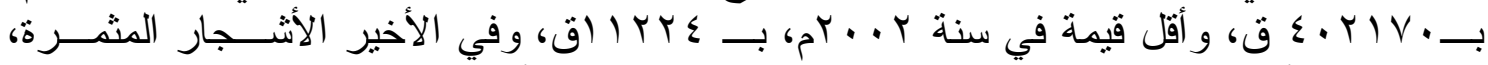

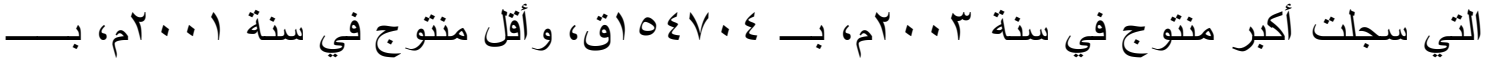

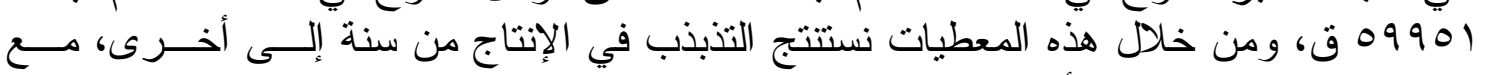

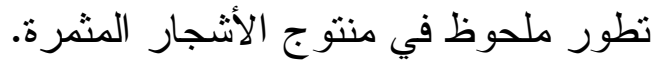

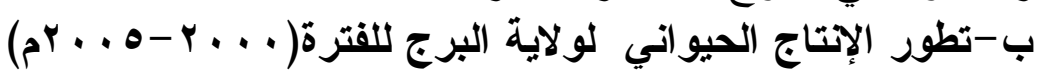

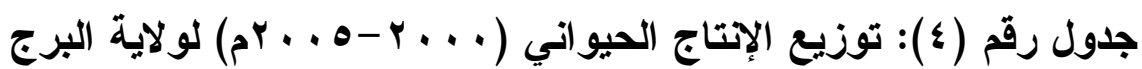

\begin{tabular}{|c|c|c|c|c|c|}
\hline عسل & البيض & الحليب & لحم أبيض & لحم أحمر & السنوات \\
\hline ヘт।. & 1 1 $79 \leqslant 1 \ldots$ & rฯ人97... & r.Tr & To9v7 & $r \ldots$ \\
\hline $17 \leqslant \ldots$ & $100 \wedge \wedge V \ldots$ & TVVYA... & YAV.r & ミ) $\leqslant$. & $r \ldots 1$ \\
\hline $11 \ldots$ & $17 \leq 7 \vee 0 \ldots$ & $r \leqslant \neg r V \ldots$ & $\varepsilon \leqslant Y \leqslant \leqslant$ & $\leqslant \wedge \leqslant 70$ & $r \ldots r$ \\
\hline r.7... & I 9 rAV.... & rqVY7... & $\sum \wedge 97$. & $\leqslant \wedge 19$. & $r \ldots r$ \\
\hline rvq.. & $r \ldots 710 \ldots$ & $r \cdot \Lambda \cdot v \cdot . \cdot$ & 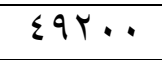 & $\varepsilon \vee \wedge \ldots$ & $r \ldots \varepsilon$ \\
\hline rᄉo.. & rщ^.rт... & $r 70.1 \ldots$ & Or^乏. & $\sum \wedge \uparrow \ldots$ & $r \ldots o$ \\
\hline
\end{tabular}

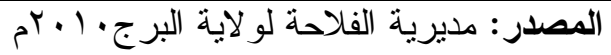

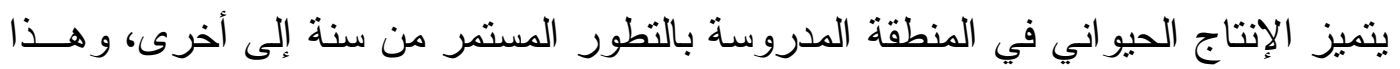

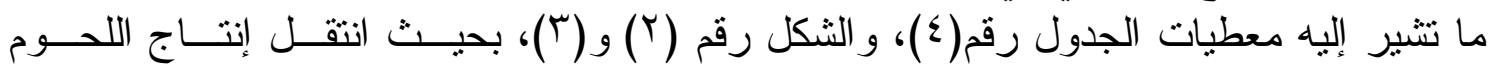

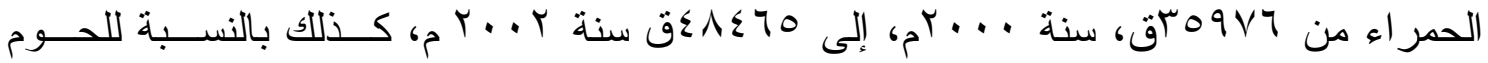

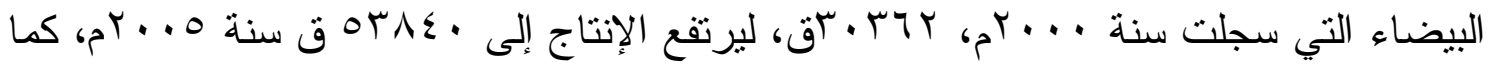

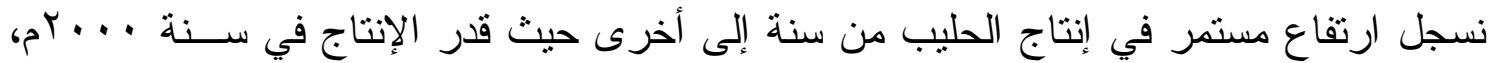

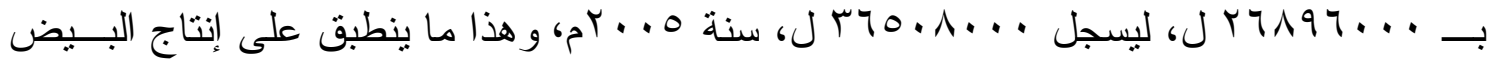

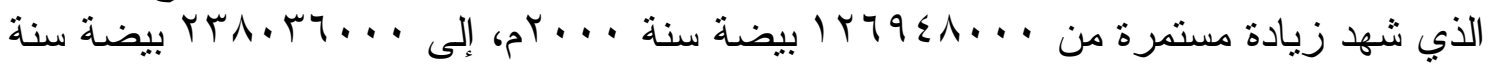

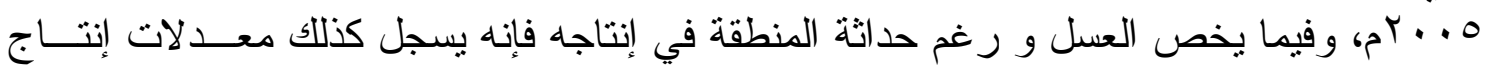

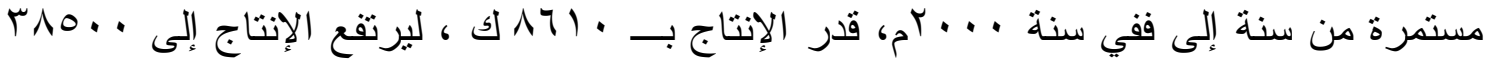

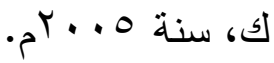
شكل رقم (r) "تطور إنتاج اللحوم الحمر اء والبيضاء في ولاية البرج للفترة( ... . -0 . . rم)"

\begin{tabular}{|l|l}
\hline 60000 \\
50000 \\
40000 \\
30000 \\
20000 & 2 \\
\hline
\end{tabular}


شكل رقم (r) "تظور إنتاج الحليب والبيض في ولاية البرج للفترة ( . . . r -ه . . rم)"

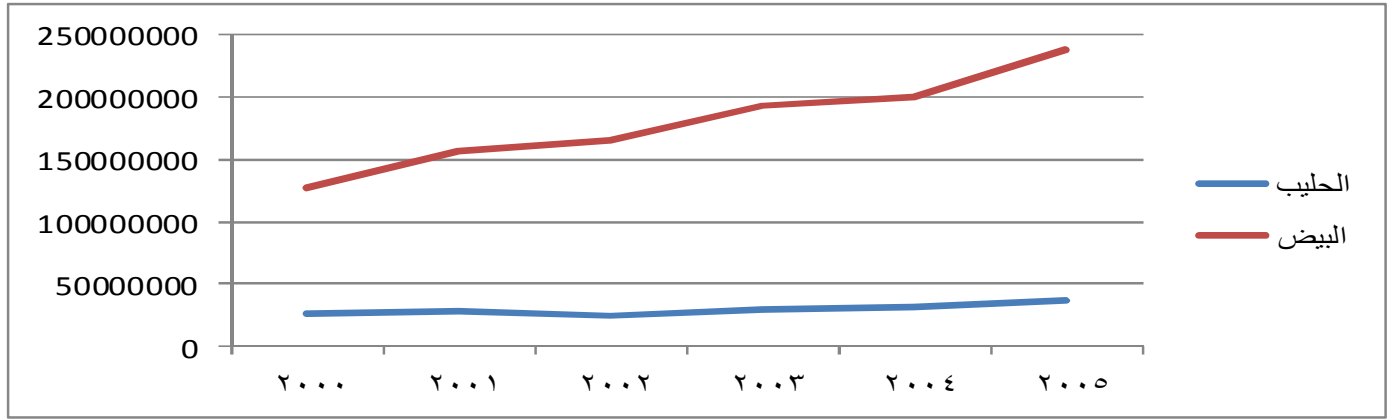

جو

جدول رقم (0): عدد مناصب الشغل المستحدثة في إطار المخطط الــوطني للتنميــة الفلاحيـة

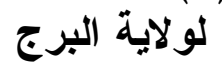

\begin{tabular}{|c|c|c|c|c|c|c|}
\hline المجموع & $r \cdot . \varepsilon$ & $r \cdot r$ & $r \cdot r$ & $r . .1$ & $r \ldots$ & السنو ات \\
\hline$r q \leqslant 7 \wedge$ & 109 & $\varepsilon \wedge \nvdash \varepsilon$ & $1 . \leqslant 10$ & $\varepsilon \ldots$ & r... & عدد العمال \\
\hline
\end{tabular}

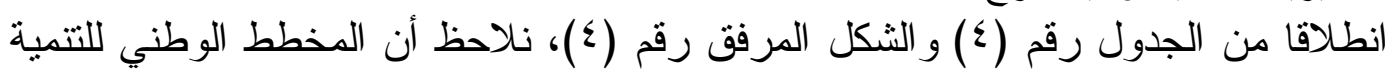

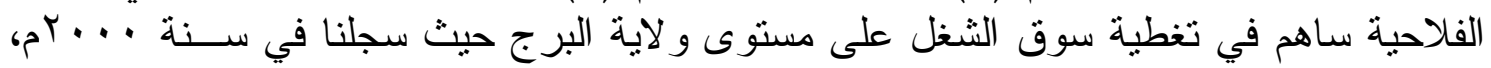

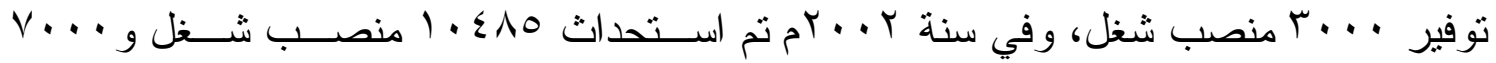

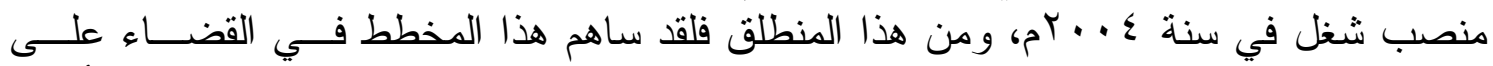

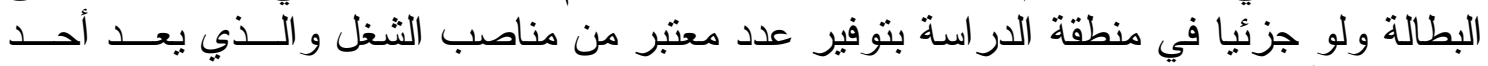

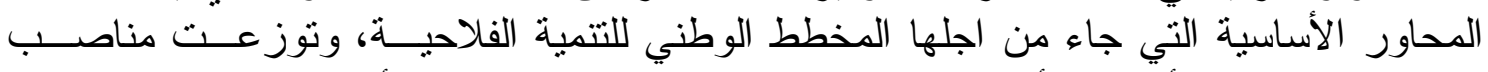

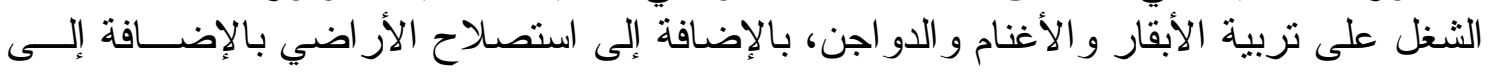

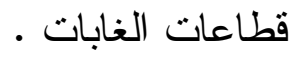

\section{شكل رقم (ع ) عدد مناصب الشغل المستحلثة في إطار المخطط الوطني للتنمية} الفلاحية لولاية البرج

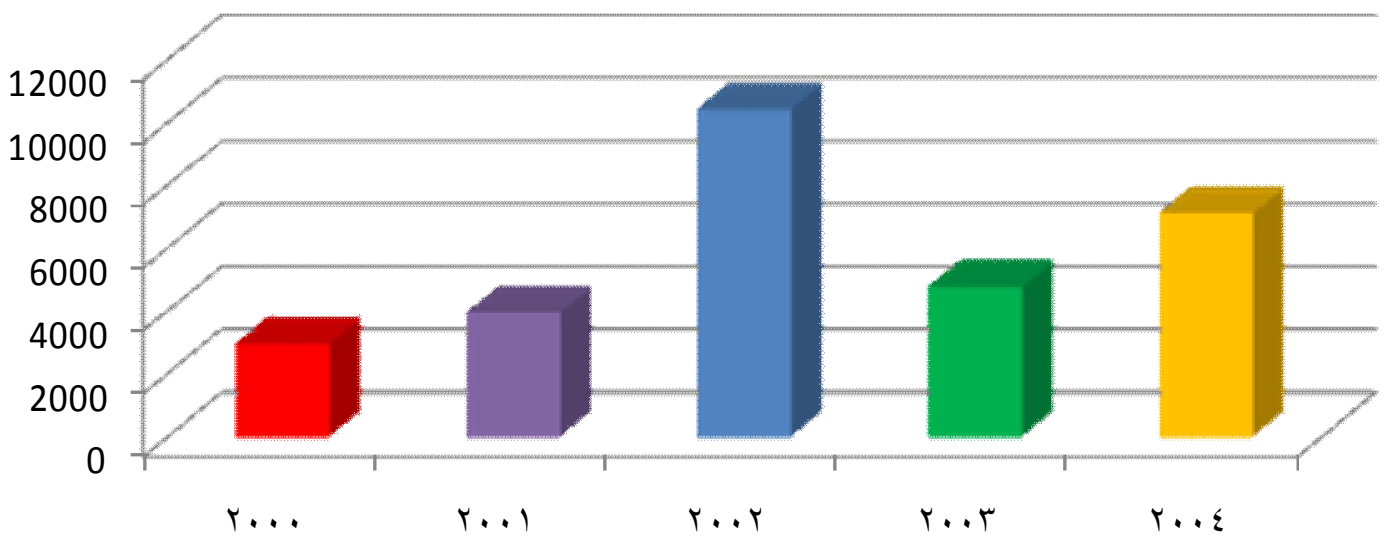


من أهم النتائج التي توصلنا إليها في هذه الدر اسة ما يلي:

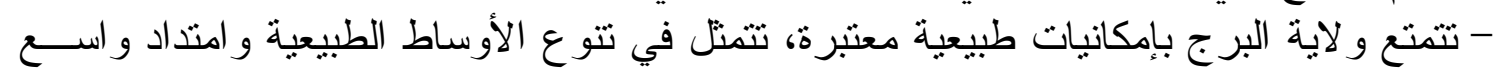

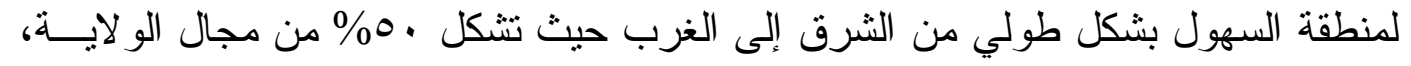

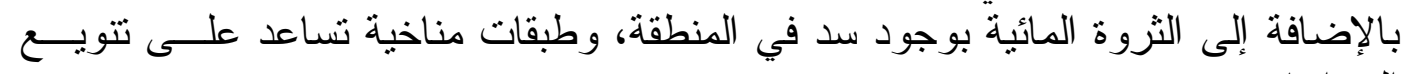

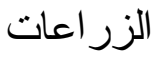

- تحتوي منطقة الدر اسة على مؤهلات بشرية حيث نلاحظ تز ايد عدد السكان من تعداد إلى اخر

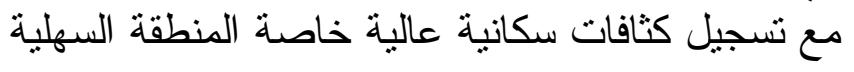

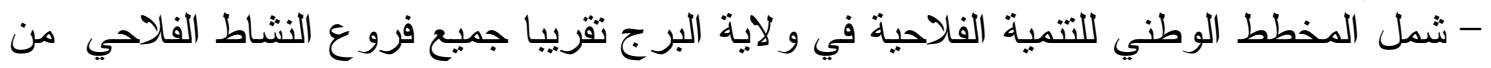

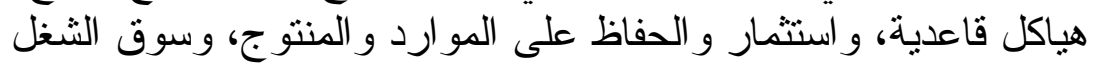

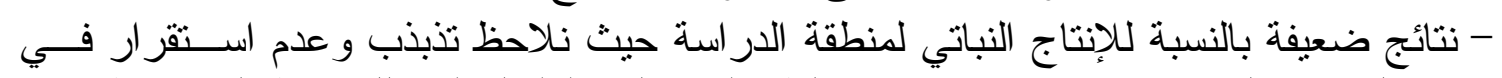

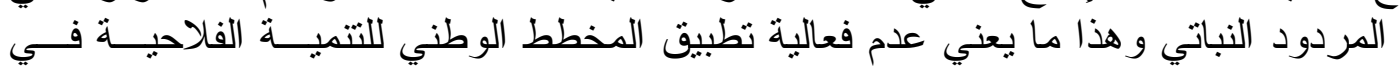
و ولاية البرج

- نتائج إيجابية بالنسبة للإنتاج الحيو اني لمنطقة الدر اسة حيث نلاحظ الزيادة في الإنتاج من سنة

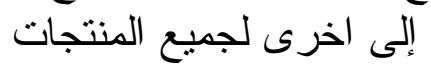
- ساهم المخطط الوطني للتنمية الفلاحية في ولاية البرج في توفير عدد مناصب شغل لا بـأس

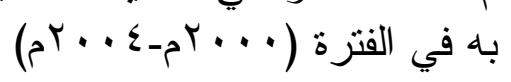
توصيات: - توسيع المساحات الزر اعية خاصة المسقية

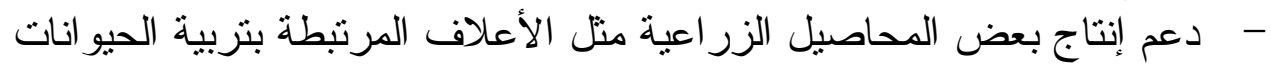

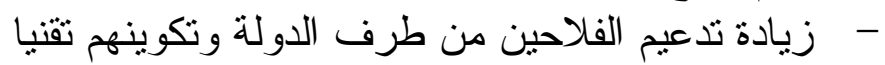

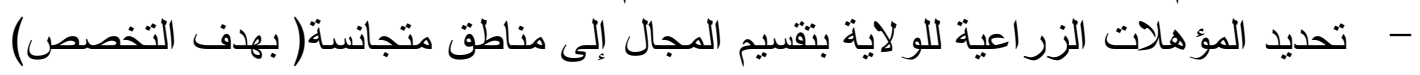

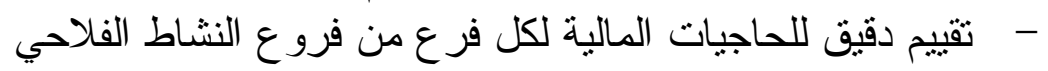

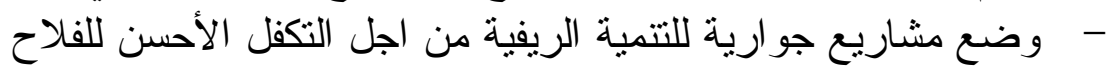

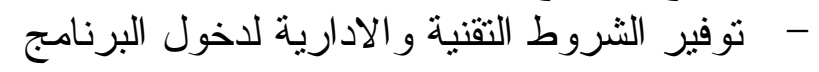

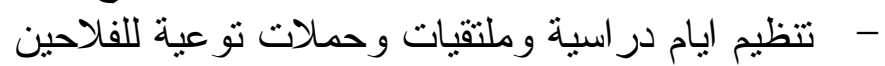
- - لا بد من مو اصلة مجهودات النتمية لرفع مستوى الفلاحة الجزئية ائرية

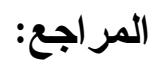

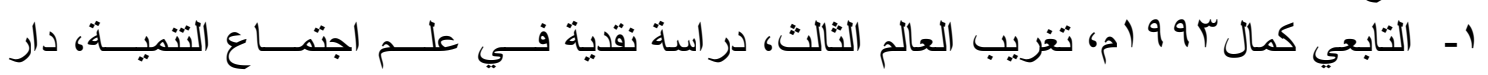

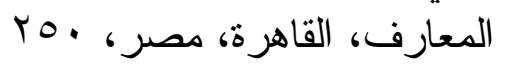

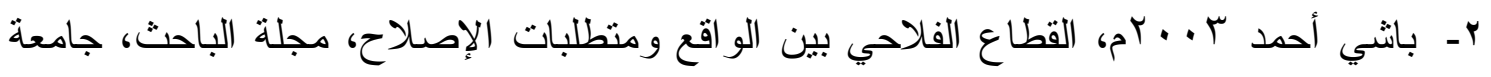

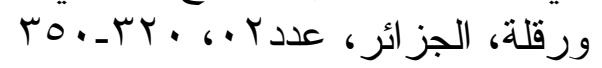

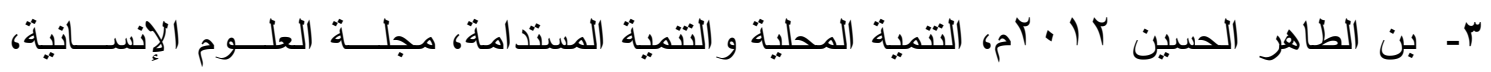

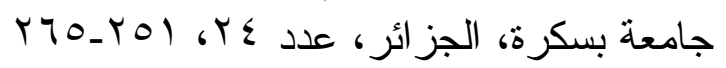

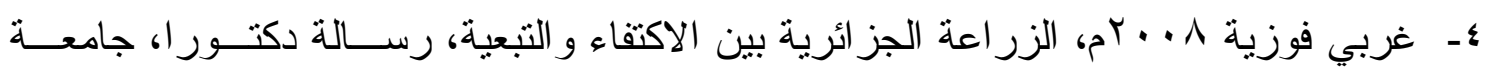

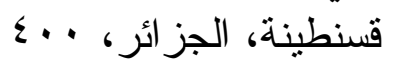

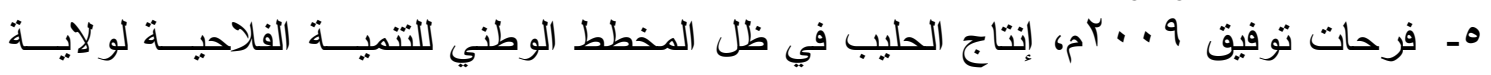

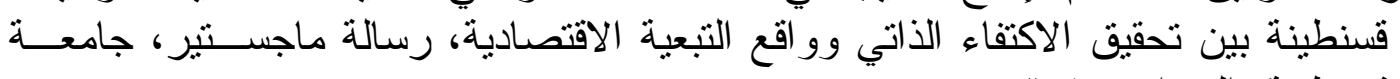

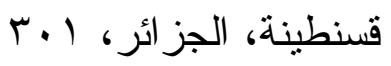

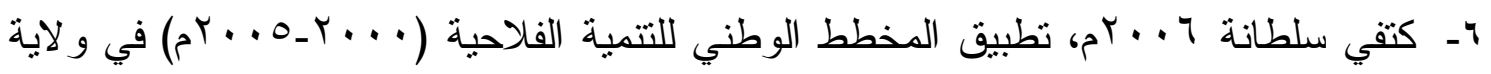

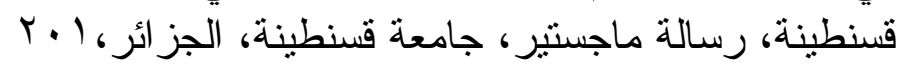




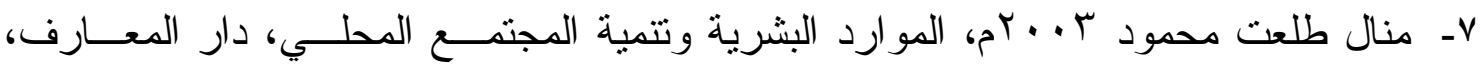

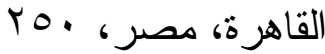

$$
\begin{aligned}
& \text { ^- منى رحمة . . . بام، السياسات الزر اعية في البلدان العربية، مركز در اسات الوحدة العربية، }
\end{aligned}
$$

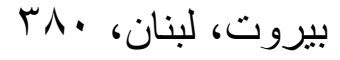

9- abdurahmane hersi 1981, les mutations des structures agraires en Algérie depuis 1962, o.p.u Alger 300

10-hadibi a et autres 2008, analyse de la mise en œuvre du plan national de développement agricole dans la première tranche du périmeter de la mitidja oust algérie, actes du 4 atelier régional du projet sima, mostaganem, algérie, 200

11-marc cote 1983, les mutations rurales en Algérie ,le cas de hautes plaines de l'est o.p.u , alger, algérie, 300

12-mourad boukella 2008, politiques agricoles, dépendence et sécurité alimentaire, éditions friedrich ebert, alger, algérie, 150

13-Pecqueur bernard 1989, le développement local, éditions Syros, paris, France 200

14-toulait hocine1988, l'agriculture algérienne les causes de l'échec, o.p.u, Alger, 350 


\title{
The Role of the National Agricultural Developement Plan in Local Developement in the Case of Algeria, the State of Willaya Bordj \\ Zohier Saifi
}

Department Earth Science (Science de la terre) Univ. Mohamed khider Biskra Alegria

\begin{abstract}
:
The agricultural sector Constitute a priority in the economic policies of Algeria since independence and highlights it through legislation and legal texts and changing real estate ownership experienced by this sector, professionals starting from the stage of self-governance in 1962 until the stage of the nineties the emergence of the National Plan for Agricultural Development, we will try in this study to identify the role of national Plan for Agricultural Development in local development at the level of the state of the bordj wilaya.
\end{abstract}

Keywords: Local development - National Plan for Agricultural Development - Local resource-enploi- production 